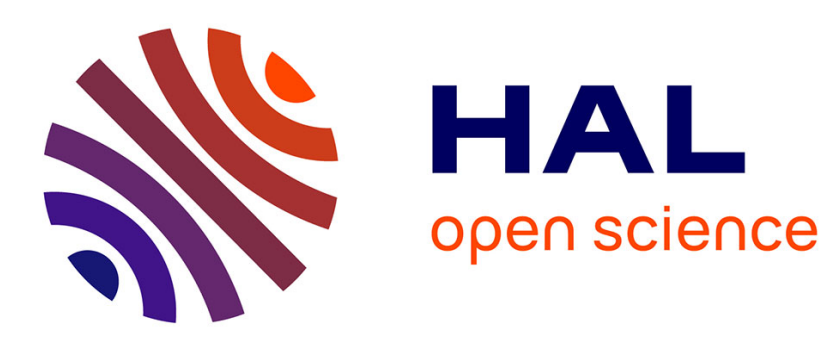

\title{
Ballistic limit equation for equipment placed behind satellite structure walls
}

\author{
F.K. Schäfer, S. Ryan, M. Lambert, R. Putzar
}

\section{To cite this version:}

F.K. Schäfer, S. Ryan, M. Lambert, R. Putzar. Ballistic limit equation for equipment placed behind satellite structure walls. International Journal of Impact Engineering, 2008, 35 (12), pp.1784. 10.1016/j.ijimpeng.2008.07.074 . hal-00542570

\section{HAL Id: hal-00542570 \\ https://hal.science/hal-00542570}

Submitted on 3 Dec 2010

HAL is a multi-disciplinary open access archive for the deposit and dissemination of scientific research documents, whether they are published or not. The documents may come from teaching and research institutions in France or abroad, or from public or private research centers.
L'archive ouverte pluridisciplinaire HAL, est destinée au dépôt et à la diffusion de documents scientifiques de niveau recherche, publiés ou non, émanant des établissements d'enseignement et de recherche français ou étrangers, des laboratoires publics ou privés. 


\section{Accepted Manuscript}

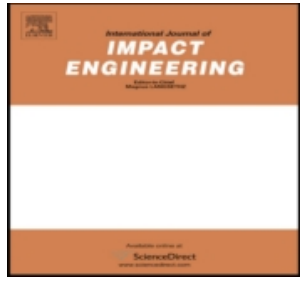

Title: Ballistic limit equation for equipment placed behind satellite structure walls

Authors: F.K. Schäfer, S. Ryan, M. Lambert, R. Putzar

PII: $\quad$ S0734-743X(08)00175-9

DOI: $\quad$ 10.1016/j.ijimpeng.2008.07.074

Reference: IE 1657

To appear in: International Journal of Impact Engineering

Received Date:

Revised Date:

Accepted Date:

Please cite this article as: Schäfer FK, Ryan S, Lambert M, Putzar R. Ballistic limit equation for equipment placed behind satellite structure walls, International Journal of Impact Engineering (2008), doi: 10.1016/j.ijimpeng.2008.07.074

This is a PDF file of an unedited manuscript that has been accepted for publication. As a service to our customers we are providing this early version of the manuscript. The manuscript will undergo copyediting, typesetting, and review of the resulting proof before it is published in its final form. Please note that during the production process errors may be discovered which could affect the content, and all legal disclaimers that apply to the journal pertain. 


\title{
Ballistic limit equation for equipment placed behind satellite structure walls
}

\author{
F.K. Schäfer ${ }^{1 *}$, S. Ryan ${ }^{1,2}$, M. Lambert ${ }^{3}$, R. Putzar ${ }^{1}$ \\ ${ }^{1}$ Ernst-Mach-Institut - Fraunhofer Institut für Kurzzeitdynamik, Eckerstr. 4, D-79104 Freiburg i. Br., Germany \\ ${ }^{2}$ School of Aerospace, Mechanical \& Manufacturing Engineering, RMIT University, GPO Box 2476V, Melbourne, Australia \\ ${ }^{3}$ ESA-ESTEC, Postbus 299, NL-2200 AG Noordwijk, The Netherlands
}

\begin{abstract}
A new ballistic limit equation has been developed for the case of a Whipple shield configuration or a sandwich panel with honeycomb core placed in front of a backwall. This "triple plate" ballistic limit equation considers explicitly the thicknesses, materials and spacings of each of the three plates. The third plate, i.e., the backwall, represents the cover plate or external wall of equipment that is placed behind the satellite structure wall. The ballistic limit equation has been calibrated with experimental results obtained from hypervelocity impact tests on satellite equipment that was placed behind typical satellite structure walls. The equipment considered were fuel and heat pipes, pressure vessels, electronics boxes, harness, and batteries, all representative of real satellite equipment. The new equation was applied to prove that if the inherent protection capability of satellite equipment against hypervelocity impacts is explicitly considered in a ballistic limit equation, the critical projectile diameters for failure of such equipment are raised considerably compared to the case where equipment is assumed to fail as soon as the structure wall that protects it is perforated.
\end{abstract}

Keywords: Triple plate ballistic limit equation, equipment vulnerability, electronics and pressure components, hypervelocity impact testing
Nomenclature
$\mathrm{Al} \quad$ Aluminum
BLC, BLE Ballistic Limit Curve, Ballistic Limit Equation
CFRP Carbon-Fibre Reinforced Plastics
H/C SP Honeycomb Sandwich Panel
MLI Multi-Layer-Insulation

*Corresponding author. Tel.: +49 7612714 421; fax: +49 76127141421.

E-mail address: schaefer@emi.fhg.de 


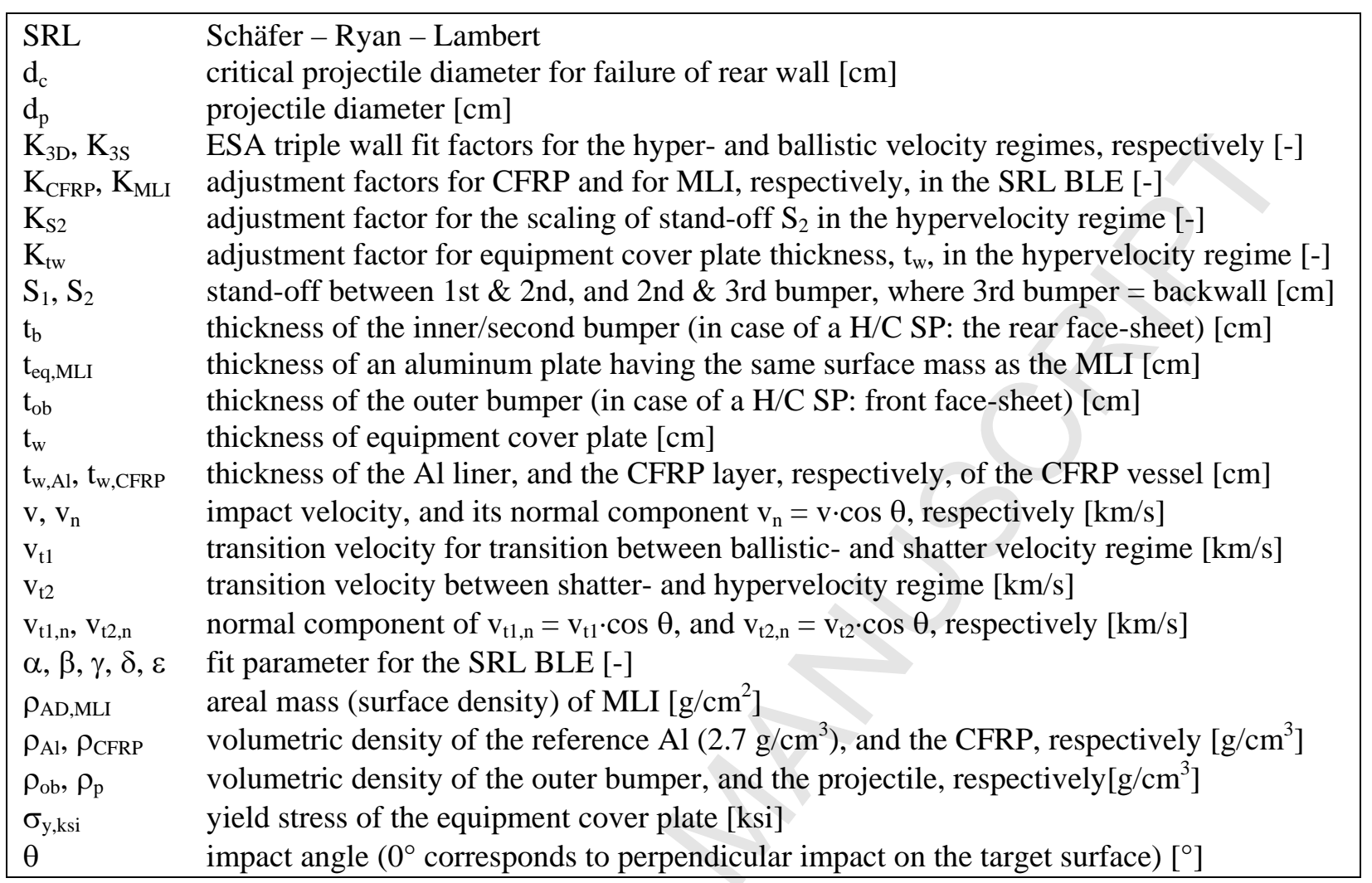

\section{Introduction}

If a satellite is hit by a space debris particle or a meteoroid large enough to perforate the structure wall of the satellite, some fraction of the mass of the particle is ejected into the interior of the satellite. In this case, the vulnerable interior equipment of the satellite may suffer substantial damage from the fragments of the impacting particle. The type of the damage to the equipment is influenced, e.g. by accommodation, integration density, residual kinetic energy of the fragments, and by the intrinsic protection capability of the equipment. Especially the latter has not yet been taken into account, neither in the design of the spacecraft primary structure, nor in the overall reliability and risk analyses of the vehicle. Consequently, the real risk for a satellite concerning mission failure due to hypervelocity impacts is currently not determined. In order to generate an improved understanding of the vulnerability of satellite equipment to hypervelocity impacts, a project was initiated by ESA/ESTEC [1]. Purpose of the project was the conduction of a systematic and comprehensive impact test campaign on satellite equipment in representative configurations of real satellites. A risk assessment was performed leading to the selection of particularly vulnerable equipment for impact testing. The considered equipment were fuel and heat pipes, pressure vessels, electronics boxes, harness, and batteries. For these types of equipment, very little impact test data were found in the open literature.

One task of the study was the development of a suitable ballistic limit equation (BLE) for application to the tested configurations. None of the published BLEs could satisfy the requirements 
because they referred to standard Whipple shields consisting of a single plate structure wall (backwall) shielded by a single plate bumper shield (e.g. Christiansen [4], Drolshagen and Borge [5], and Reimerdes et al. [6]). For mapping the tested configurations, a "triple plate” BLE was required: the first and second plates correspond to the face-sheets of the honeycomb sandwich panel structure wall of the satellite (the honeycomb core is omitted) while the third plate corresponds to the front side of the interior satellite equipment.

Ballistic limit equations relating to configurations with three plates have been published previously by Christiansen [4] and Christiansen et al. [7] for stuffed Whipple shields, which can be regarded as a special class of triple plate shields. However, these equations do not consider explicitly all different plate thicknesses and spacings. Reimerdes et al. [6] presents a triple plate BLE that considers explicitly all plate thicknesses, materials, and spacing. Reimerdes's equation computes the ballistic limit projectile diameter in a recursive way, which complicates its use in risk analysis tools. Also, this equation was designed for use with double bumper shields for ESA's Columbus module onboard the International Space Station; hence, it was calibrated for this application case only. To overcome the above shortcomings, a new linear triple plate BLE was developed that was calibrated using the test results from [1]. It was termed SRL equation.

\section{Impact Test Campaign}

In this paragraph, an overview of the impact test campaign from [1] is provided. To reflect the actual configurations used onboard the spacecraft in a reasonably realistic way, the equipment was placed at defined spacing behind (a) sandwich panels with aluminum honeycomb core and MLI (typical for satellites), (b) standalone MLI (typical for satellites), or (c) single bumper plates or double bumper plates (typical for manned spacecraft). The resulting test configurations were:

1. fuel pipes placed behind (a) Al H/C SP structure walls, with MLI, and (b) thin bumper plates

2. heat pipes placed behind Al H/C SP structure walls, with MLI, and (b) heat pipes integrated in sandwich panels

3. carbon-fibre overwrapped Al vessels placed behind (a) Al H/C SP structure walls, with MLI, and (b) double plate bumpers

4. battery cells placed behind $\mathrm{Al} \mathrm{H/C} \mathrm{SP} \mathrm{structure} \mathrm{walls,} \mathrm{with} \mathrm{MLI}$

5. e-boxes placed behind (a) Al H/C SP structure walls, with MLI, and (b) standalone MLI, and

6. harnesses placed behind (a) Al H/C SP structure walls, with MLI, and (b) standalone MLI

The test campaign comprised 89 hypervelocity impact tests on operating equipment in configurations representative for satellites, cf. [1] to [3], with impact velocities ranging between $2.26 \mathrm{~km} / \mathrm{s}$ and $7.79 \mathrm{~km} / \mathrm{s}$, and projectile sizes of $1.1 \mathrm{~mm}$ to $7.0 \mathrm{~mm}$. The vast majority of the impact tests were conducted at perpendicular incidence, i.e. at $0^{\circ}$ impact obliquity. The rationale of the impact test campaign was to increase the projectile diameter and/or the impact velocity until failure of the equipment occurred. Failure modes for pressurized equipment (such as high-pressure vessels, propellant tanks, fuel pipes, heat pipes) were defined in a straightforward way, e.g. leakage or catastrophic rupture. For electronic equipment (such as electronics boxes, harnesses, batteries), failure modes had to be investigated and were defined through the outcome of impact tests. These failure modes comprised temporary out-of-order, voltage spikes, or permanent failure. In the following, selected results of the impact tests on pressure vessels and electronics boxes are presented. 


\subsection{Example 1: hypervelocity impact tests on vessels}

The carbon-fibre overwrapped $\mathrm{Al}$ vessels were manufactured as cylindrical vessels with isotensoid-shaped caps. The high-pressure vessels had an aluminum liner with a thickness of $(1.05+0.35 /-0.25) \mathrm{mm}$, overwrapped with a $(2.9 \pm 0.2) \mathrm{mm}$ thick layer of CFRP. The inner diameter of the vessels was $204 \mathrm{~mm}$, the length of the cylindrical part was $400 \mathrm{~mm}$. The vessels were inflated with nitrogen to $9 \mathrm{MPa}$ prior to shooting. A typical set-up is shown in Fig. 1: The satellite structure wall was simulated by a piece of sandwich panel with Al honeycomb core and Al face-sheets and MLI attached on top of it, the vessel was placed at a defined stand-off behind the structure $(200 \mathrm{~mm})$ to simulate realistic accommodation condition onboard satellites. At constant impact velocity of $6.5 \mathrm{~km} / \mathrm{s}$, the target damage was increased by raising the diameter of the Al projectiles: At $4.5 \mathrm{~mm}$ diameter (Al sphere), just a few craters have been generated in the wall; at $5.0 \mathrm{~mm}$ diameter, the vessel wall was perforated; with a projectile diameter of $6.0 \mathrm{~mm}$, the vessel ruptures catastrophically.

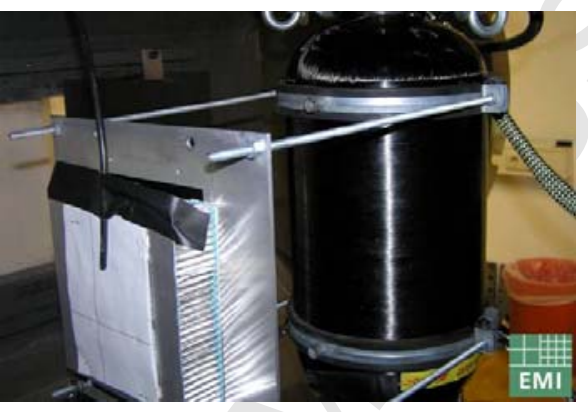

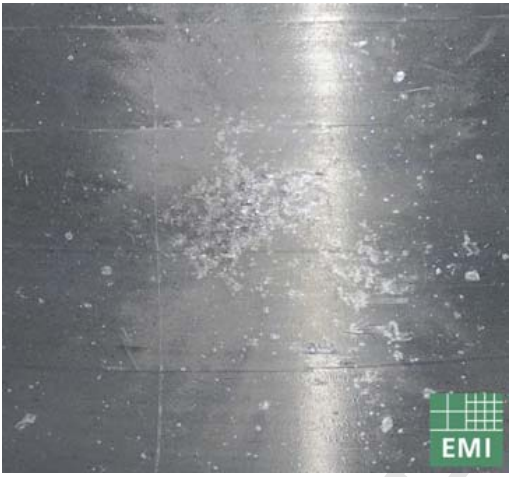

EMI No. 4755, $S=100 \mathrm{~mm}$, $d_{p}=4.5 \mathrm{~mm}, v=6.5 \mathrm{~km} / \mathrm{s}$ craters only

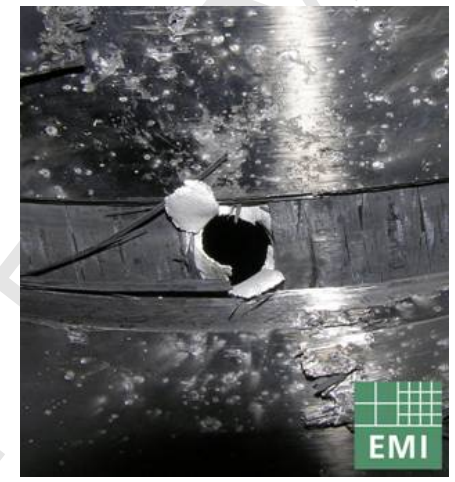

EMI No. 4757, $S=100 \mathrm{~mm}$, $d_{p}=5.0 \mathrm{~mm}, v=6.5 \mathrm{~km} / \mathrm{s}$ perforation hole

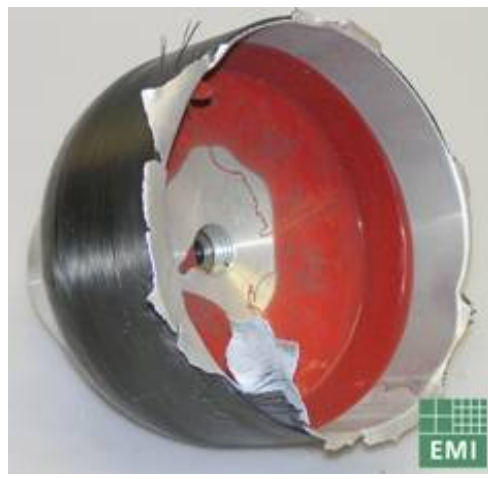

EMI No. 4754, $S=200 \mathrm{~mm}$, $d_{p}=6.0 \mathrm{~mm}, v=6.5 \mathrm{~km} / \mathrm{s}$ catastrophic rupture

Fig. 1. Top: Set-up for impact test on high-pressure vessel with structure wall consisting of sandwich panel with Al honeycomb core and MLI on top of it. Bottom: Test results and failure modes for three different impact conditions on shielded high-pressure vessels. 


\subsection{Example 2: hypervelocity impact tests on electronics boxes}

To simulate electronics in flight-representative configurations, simplified computers were designed. These so-called e-boxes consist of an Al casing with a populated printed circuit board inside (Fig. 2). They were protected by a covering Al lid with a thickness of $1 \mathrm{~mm}$ to $3 \mathrm{~mm}$. The e-box was in a computing mode while it was impacted. In Fig. 2, a configuration relating to e-boxes placed behind a standalone MLI "structure wall" is shown. Typical stand-offs of the structure walls amounted to between $0 \mathrm{~mm}$ and $300 \mathrm{~mm}$. Depending on the impact conditions and the corresponding damages, the observed failure modes of the e-boxes ranged from temporary disruptions of computing power that disappeared during several hundreds of microseconds or milliseconds after the impact to complete failure of the e-box. It was common to all experiments that failure of the e-box only occurred in such tests that resulted in detached spallation or worse damage in the e-box lid. Hence, detached spall or clear hole perforation of the e-box lid is considered a necessary condition for the initiation of e-box failure.
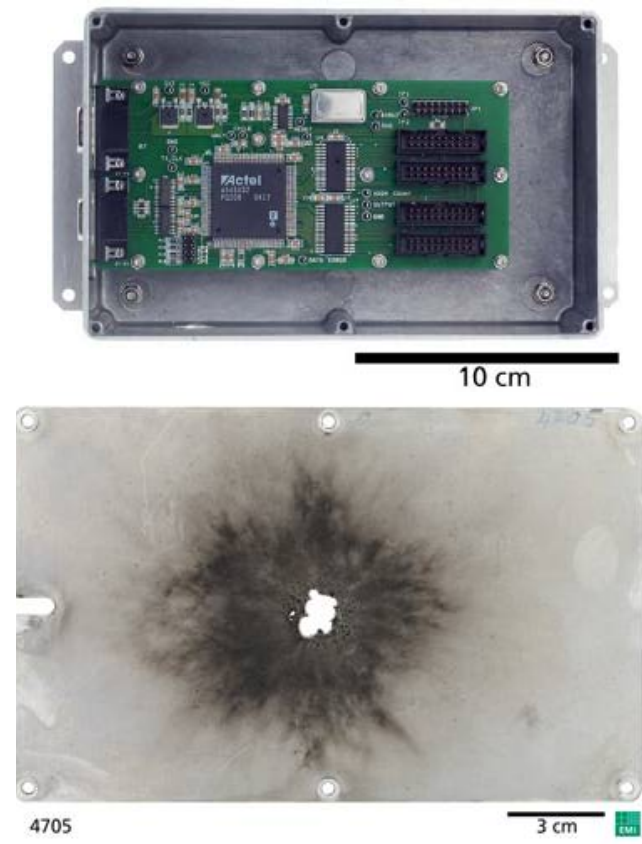
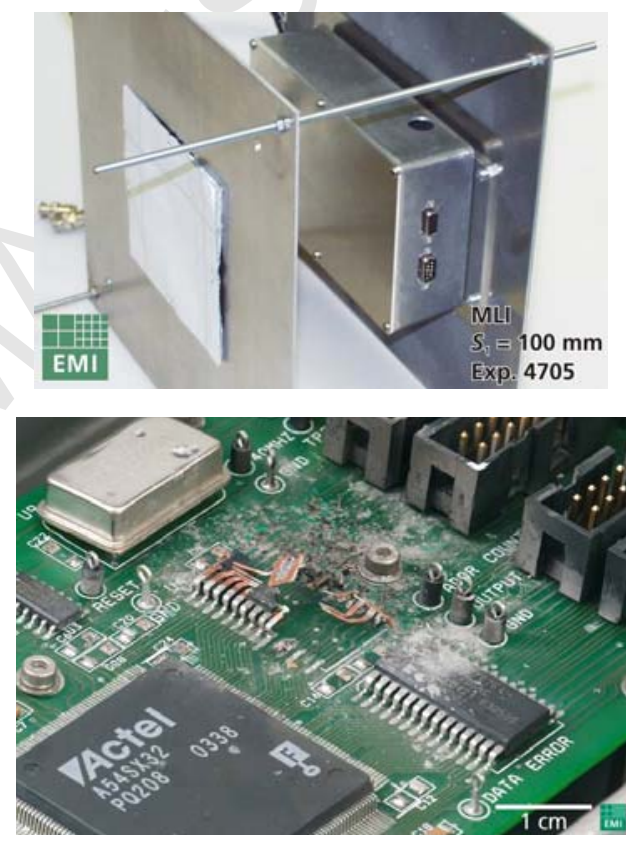

Fig. 2. Top: E-box interior front view, without covering lid (left) and in typical impact configuration, for Exp. 4705 (right). Bottom: Exp. 4705, configuration consisting of MLI structure wall, spacing $100 \mathrm{~mm}, 2.0 \mathrm{~mm}$ thick e-box lid, $2.8 \mathrm{~mm}$ diameter projectile, impact velocity $6.5 \mathrm{~km} / \mathrm{s}$, impact angle $0^{\circ}$; electronics was destroyed.

\section{SRL Ballistic Limit Equation}

As outlined above, the new ballistic limit equation needed to be capable of considering explicitly the thicknesses, materials, and spacing of each of three plates (Fig. 3). The first and the second plates represent the spacecraft's structure wall (e.g. honeycomb sandwich panel of a satellite, or bumper and 
primary structure of a manned spacecraft), the third plate represents the front wall or cover plate of the equipment under consideration. As this is just a very generic configuration, there is a need to define a list of assumptions. Further, to allow completely different equipment types to be considered ranging from cables to e-boxes and heat pipes to propellant tanks requires definition of a number of application notes specific to each equipment type.

$$
\text { spacecraft structure wall }
$$

equipment front wall / cover plate
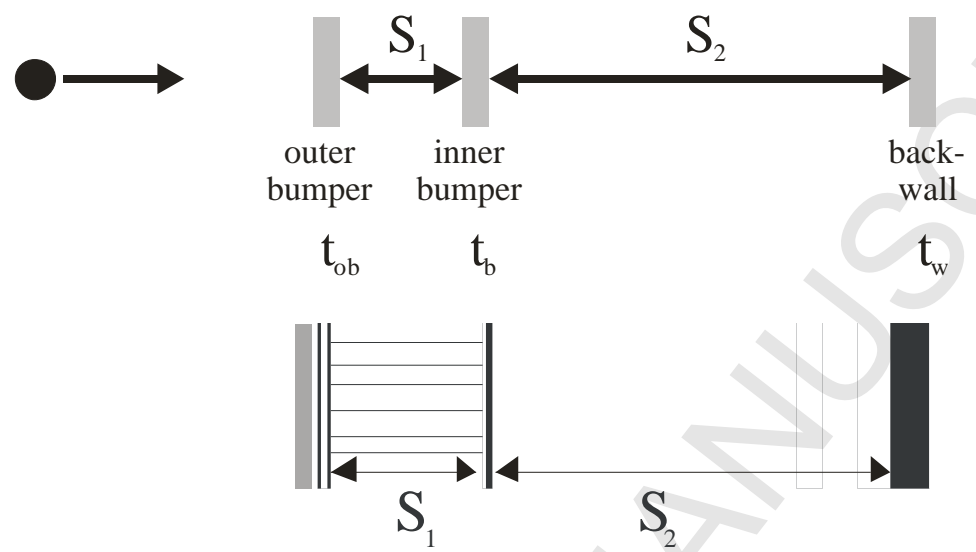

Fig. 3. Principle set-up for SRL ballistic limit equation geometry case.

As a failure criterion for the new equation, the criterion proposed by Christiansen in [1] was adopted for the rear wall of a Whipple shield: Failure is reached if any damage equal to or worse than spall detachment from the equipment cover plate's rear side occurs. This criterion works fine when used with pressure equipment, e-boxes, and batteries. However, in the case of, e.g., harnesses, the failure criterion has to be related to severing. It should also be noted that perforation of equipment or the severing of cables does not necessarily imply that the equipment ceases operation. The effect of failure probability of equipment following a hypervelocity impact in terms of its operation has been investigated in depth in [1].

The corresponding configurations, for which the SRL BLE can be applied (and for which it has been calibrated), are:

- standalone $\mathrm{Al} \mathrm{H/C}$ sandwich panels (including a layer of MLI)

- $\mathrm{Al} \mathrm{H/C}$ sandwich panels (including a layer of MLI) with a plate placed behind it

- single bumper shielded plates (bumper may by either MLI or a thin metallic plate)

- double bumper shielded plates

The SRL BLE uses a notation similar to the one introduced by ESA [5], who use two coefficients, $K_{3 S}$ and $K_{3 D}$, that can be adjusted to fit to experimental ballistic limit data. Incidentally, for $K_{3 S}=1$ and $\mathrm{K}_{3 \mathrm{D}}=0.16$, the equation presented by ESA [5] and the equation presented by Christiansen [4] yield exactly the same result (except that [4] specifies a limiting angle, above which $d_{c}$ remains constant, in contrast to [5], where no limit angle criterion is applied). Accordingly, the new equation was designed to converge to the Whipple shield equation of Christiansen [4] in the limiting cases of $\left(t_{w}\right) \rightarrow 0$ or 
$\left(S_{2}\right) \rightarrow 0$. The new SRL BLE can be applied in a straightforward way in risk analysis tools for equipment placed behind spacecraft structure walls.

\subsection{SRL ballistic limit equation}

Eqn. (1) shows the critical projectile diameter as a function of impact velocity in the ballistic velocity regime $\left(\mathrm{v}_{\mathrm{n}} \leq \mathrm{v}_{\mathrm{t} 1, \mathrm{n}}\right)$. In the ballistic velocity regime, it is assumed that the projectile does not fragment and, hence, the protection offered by the target essentially stems from the amount of mass in the line of sight of the projectile. To fit the data to the equation, the power of $\alpha$ has been added to the wall thickness of the equipment cover plate $t_{w}$. Further, a term taking care of the protection enhancement from the MLI $\left(\mathrm{K}_{\mathrm{MLI}} \cdot \mathrm{t}_{\mathrm{eq}, \mathrm{MLI}}\right)$ has been added.

$$
d_{c}(v)=\left[\frac{\frac{\left(t_{w}^{\alpha}+t_{b}\right)}{K_{3 S}} \cdot\left(\frac{\sigma_{y, k s i}}{40}\right)^{1 / 2}+t_{o b}+K_{M L I} \cdot t_{e q, M L I}}{0.6 \cdot(\cos \theta)^{\delta} \cdot \rho_{p}^{1 / 2} \cdot v^{2 / 3}}\right]^{18 / 19} \quad \text { where } t_{e q, M L I}=\frac{\rho_{A D, M L I}}{\rho_{o b}}
$$

In the shatter velocity regime, a linear extrapolation is made between the ballistic (Eqn. (1)) and the hypervelocity regime (Eqn. (3), below). The following equation describes the critical projectile diameter for failure of rear wall, $\mathrm{d}_{\mathrm{c}}$, in the shatter velocity regime $\left(\mathrm{v}_{\mathrm{t} 1, \mathrm{n}}<\mathrm{v}_{\mathrm{n}}<\mathrm{v}_{\mathrm{t} 2, \mathrm{n}}\right)$ :

$$
d_{c}(v)=d_{c}\left(v_{t 1}\right)+\frac{d_{c}\left(v_{t 2}\right)-d_{c}\left(v_{t 1}\right)}{v_{t 2}-v_{t 1}} \cdot\left(v-v_{t 1}\right)
$$

In the equation for the critical projectile diameter in the hypervelocity regime $\left(\mathrm{v}_{\mathrm{n}} \geq \mathrm{v}_{\mathrm{t} 2, \mathrm{n}}\right)$, Eqn. (3), a term $\mathrm{K}_{\mathrm{S} 2} \cdot \mathrm{S}_{2}{ }^{\beta} \cdot \mathrm{t}_{\mathrm{w}}{ }_{\mathrm{w}} \cdot \cos \theta^{\varepsilon}$ has been added to explicitly consider equipment placed behind structure walls. $\mathrm{S}_{2}$ is the stand-off between the rear side of the inner bumper and the equipment front/cover plate. $t_{w}$ is the equipment cover plate thickness, and $\theta$ the impact angle of the projectile on the target surface. The additional cosine-term introduced in this part of the equation was necessary to reflect the experimentally observed tremendous increase of critical projectile diameters in the hypervelocity range at oblique impacts. The data obtained also suggest that stand-off $S_{2}$ contributes significantly to the enhancement of the protection capability at hypervelocity. The exponents of $S_{2}, t_{w}$, $\cos \theta$ have to be fit to the experimental data. Fit factor $\mathrm{K}_{\mathrm{S} 2}$ is required to balance the term $\mathrm{S}_{2}{ }^{\beta} \cdot \mathrm{t}_{\mathrm{w}}{ }^{\gamma} \cdot \cos \theta^{\varepsilon}$ as all fit parameters $\mathrm{K}_{\mathrm{S} 2}, \beta, \gamma$, and $\varepsilon$ are inter-related. Hence, changing one fit parameter requires adjustment of at least one of the other parameters. Further, the wall thickness $t_{w}$ of the equipment cover plate multiplied by a fit factor $K_{t w}$ has been added to $t_{b}$. The sum term $t_{b}+K_{t w} \cdot t_{w}$ represents an effective thickness of inner bumper and equipment cover plate ("effective" because of the $\mathrm{K}_{\mathrm{w}}$-term). Its significance becomes obvious when considering a case where the equipment is mounted directly on the inner bumper of the structure wall $\left(\mathrm{S}_{2}=0\right)$. This case essentially corresponds to a Whipple shield with an outer bumper and a rear wall constituted by the inner bumper plus the equipment cover plate. It can be shown that the 
penetration resistance of two plates with zero spacing is larger than the penetration resistance of a plate with a thickness equal to the sum of the thicknesses of the two plates. This can be explained by shockwave reflection at the interface of the two plates, which effectively increases the penetration resistance of the wall to impacting fragments. By introducing $\mathrm{K}_{\mathrm{tw}}$ as a fit factor to impact experiments, this effect can be considered.

To apply this equation for the calculation of a BLC of a standalone sandwich panel, $t_{w}$ and $S_{2}$ are set to zero. The equation then essentially reduces to the ESA triple wall equation [5] or the Whipple shield equation [4], respectively. To apply it for the case of, e.g., an e-box attached directly to a honeycomb sandwich panel structure wall, $S_{2}$ has to be set equal to zero. The following equation describes the critical projectile diameter for failure of the rear wall, $d_{c}$, in the hypervelocity regime $\left(\mathrm{v}_{\mathrm{n}} \geq \mathrm{v}_{\mathrm{t} 2 \mathrm{n}}\right)$ :

$$
d_{c}(v)=\frac{1.155 \cdot\left(S_{1}^{1 / 3} \cdot\left(t_{b}+K_{t w} \cdot t_{w}\right)^{2 / 3}+K_{S 2} \cdot S_{2}^{\beta} \cdot t_{w}^{\gamma} \cdot(\cos \theta)^{-\varepsilon}\right) \cdot\left(\frac{\sigma_{y, k s i}}{70}\right)^{1 / 3}}{K_{3 D}^{2 / 3} \cdot \rho_{p}^{1 / 3} \cdot \rho_{o b}^{1 / 9} \cdot v^{2 / 3} \cdot \cos \theta^{\delta}}
$$

\subsection{Assumptions for the SRL equation}

Assumption 1 (Lateral extension of the equipment cover plate): The equipment front side, termed $\mathrm{t}_{\mathrm{w}}$ in Fig. 3 and spaced $S_{2}$ from the second bumper, is infinitely extended in lateral direction. Hence, any fragment that is ejected downrange from the rear side of the second bumper (termed $t_{b}$ ) encounters the equipment front wall.

Assumption 2 (Material of the equipment cover plate): The equipment front wall consists of just one material. This assumption implies that $t_{w}$ has to be defined for each piece of equipment separately. E.g. e-boxes and battery cells have planar metallic plates as covers or casing walls, respectively, hence, material and thickness of $\mathrm{t}_{\mathrm{w}}$ can be defined in a straightforward way. Carbon-fibre wrapped vessels and cables are composed of two or more different constituents. Thus, for such targets, definition of an equivalent wall thickness is required, cf. application notes.

Assumption 3 (Treatment of honeycomb sandwich panels): In case a honeycomb sandwich panel is used as spacecraft structure, the space-facing (front) face-sheet of the sandwich panel corresponds to the outer bumper $\left(\mathrm{t}_{\mathrm{ob}}\right)$ while the rear face-sheet corresponds to the inner bumper $\mathrm{t}_{\mathrm{b}}$. The honeycomb core has thickness $S_{1}$ but its physical effect on the penetration process is ignored. Hence, the honeycomb core is effectively replaced by void. The effect of the honeycomb core on the protection capability is taken into account by the fit coefficients and the $\cos \theta$ angle dependence of the BLE.

Assumption 4 (Effect of MLI): MLI placed on the outward facing face-sheet of the honeycomb sandwich panel is taken into account by effectively increasing the face-sheet thickness with an amount of aluminum equal to the surface mass of the MLI, $\mathrm{t}_{\mathrm{eq}, \mathrm{MLI}}$, multiplied by an adjustment factor. The adjustment factor, $\mathrm{K}_{\mathrm{MLI}}$, always exceeds 1 . It takes into account the effective improvement of protection typically observed when using MLI on top of structure walls. In this case, the MLI behaves as a thin multi-shock shield. It needs to be noted that in other test campaigns it was shown that use of MLI on top of the structure walls may also degrade the protective performance of a shielding system (e.g. ATV Whipple shield configuration [8]).

Assumption 5 (Applicable impact angle range): Because the SRL equation has been fit mostly to 
test data obtained in perpendicular impact tests (i.e. at $0^{\circ}$ ), it is best validated for normal impacts. It was also fitted against a rather low number of oblique impact tests at $45^{\circ}$. Additionally, it has been fitted to test results from earlier test campaigns on (standalone) honeycomb sandwich panels covering the impact obliquity range of $0^{\circ}$ to $70^{\circ}$. The SRL equation has no limitations on the impact angle, however, considering the limited data available it requires definitely validation at oblique impact angles in future test campaigns.

All other assumptions and coefficients were adopted from the ESA triple wall equation.

\subsection{Application notes for the SRL ballistic limit equation}

In this chapter, application notes for the SRL BLE are listed and fit parameters are defined.

\subsubsection{Application to structure walls}

(S1) MLI with stand-off to equipment $>0$ : In case standalone MLI is used as the structure wall, the SRL equation essentially is applied as Whipple shield equation. $S_{2}$ is set to zero and $S_{1}$ corresponds to the inner spacing between the MLI and the equipment cover plate. $t_{\mathrm{ob}}$ shall be set to zero. The MLI structure wall is explicitly considered in the BLE (in the ballistic velocity regime) as $t_{\text {eq,MLI }}$ where $t_{\text {eq,MLI }}$ is calculated from the MLI areal mass divided by the (volumetric) density of aluminum $\left(2.7 \mathrm{~g} / \mathrm{cm}^{3}\right)$ $t_{\text {eq,MLI }}=\rho_{\mathrm{AD}, \mathrm{MLI}} / \rho_{\mathrm{Al}}$. For $\mathrm{t}_{\mathrm{b}}$, the thickness of the casing wall shall be inserted. For the transition velocities $\mathrm{v}_{\mathrm{t} 1, \mathrm{n}}$ and $\mathrm{v}_{\mathrm{t} 2, \mathrm{n}}, 4 \mathrm{~km} / \mathrm{s}$ and $10 \mathrm{~km} / \mathrm{s}$, respectively, shall be used.

(S2) MLI placed directly on top of equipment: The equation for the critical diameter in the ballistic velocity regime is applied to the whole velocity regime $v_{n}>0 . t_{o b}$ and $t_{w}$ are set to zero. $t_{e q, M L I}$ is calculated from the MLI areal mass divided by the (volumetric) density of aluminum $\left(2.7 \mathrm{~g} / \mathrm{cm}^{3}\right)$ $t_{\text {eq,MLI }}=\rho_{\mathrm{AD}, \mathrm{MLI}} / \rho_{\mathrm{Al}}$. This equation effectively corresponds to the Cour-Palais thin wall equation.

(S3) Standalone equipment cover: This configuration corresponds to direct impacts on unshielded equipment, i.e. impacts on thin plates. Same procedure as (S2), except that $t_{\text {eq,MLI }}$ is set to zero.

(S4) Single wall shielding: With equipment placed behind a single wall shield, this configuration corresponds to a Whipple shield. Insert the wall thickness of the single wall bumper for $\mathrm{t}_{\mathrm{ob}}$. Set $\mathrm{t}_{\mathrm{w}}$ and $\mathrm{S}_{2}$ equal to zero.

(S5) Honeycomb sandwich panels: The honeycomb core of a honeycomb sandwich panel is omitted; it shall be replaced by void. The thickness of the honeycomb is the $S_{1}$ spacing. $S_{2}$ is the closest spacing between the second bumper and the equipment surface (in normal direction to the plane of the second bumper plate). MLI placed on top of the honeycomb sandwich panel is considered explicitly in the BLE (in the ballistic velocity regime) as $t_{\text {eq,MLI }}$ where $t_{\text {eq,MLI }}$ is calculated from the MLI areal mass divided by the (volumetric) density of the aluminum alloy used for the outer face-sheet.

(S6) Double wall shielding: The outer bumper with thickness $t_{\mathrm{ob}}$ corresponds to the first bumper of the double wall shield. The inner bumper with thickness $t_{b}$ corresponds to the second bumper of the double bumper shield. $S_{1}$ is the inner spacing between first and second bumper, $S_{2}$ is the closest spacing between the second bumper and the equipment surface (in normal direction to the plane of the second bumper plate). For $\sigma_{y, k s i}$, the yield stress of the equipment cover wall shall be used. MLI placed on top of the outer bumper is considered explicitly in the BLE (in the ballistic velocity regime) as teq,MLI where $t_{\text {eq,MLI }}$ is calculated from the MLI areal mass divided by the (volumetric) density of the aluminum alloy used for the outer bumper. 


\subsubsection{Application to equipment}

(E1) Application to fuel pipes: Equipment placed behind structure walls (S1) to (S4): For $t_{b}$, use the value of the pipe's wall thickness. If the pipe material is other than aluminum, use for $t_{b}$ the value as obtained from the equal areal density approach with the density of aluminum for normalization $\left(t_{b}=t_{\text {pipe }} \cdot \rho_{\text {pipe }} / \rho_{\text {Al }}\right)$. For the yield stress $\sigma_{\text {y.ksi }}$, use the yield stress of the actual pipe material. Equipment placed behind structure walls (S5) to (S6): For $t_{w}$, use the value of the pipe's wall thickness. If the pipe material is other than aluminum, use for $t_{w}$ the value as obtained from the equal areal density approach with the density of aluminum for normalization $\left(t_{w}=t_{\text {pipe }} \cdot \rho_{\text {pipe }} / \rho_{\text {Al }}\right)$. For the yield stress $\sigma_{y . k s i}$, use the yield stress of the actual pipe material.

(E2) Application to standalone heat pipes: Equipment placed behind structure walls (S1) to (S4): For heat pipes, two wall thicknesses are supplied: minimum and maximum wall thickness (Fig. 4). For the SRL equation, use the maximum wall thickness for $t_{b}$; if the heat pipe material is other than aluminum, use for $t_{b}$ the value as obtained from the equal areal density approach $\left(t_{b}=t_{\text {pipe }} \cdot \rho_{\text {pipe }} / \rho_{\text {Al }}\right)$. Set $t_{w}$ and $S_{2}$ equal to zero. For the yield stress $\sigma_{y . k s i}$, use the yield stress of the actual heat pipe material. Equipment placed behind structure walls (S5) to (S6): For heat pipes, two wall thicknesses are supplied: minimum and maximum wall thickness (Fig. 4). For the SRL equation, use the maximum wall thickness for $t_{w}$. If the heat pipe material is other than aluminum, use for $t_{w}$ the value as obtained from the equal areal density approach described above $\left(t_{\mathrm{w}}=\mathrm{t}_{\text {pipe }} \cdot \rho_{\text {pipe }} / \rho_{\mathrm{Al}}\right)$. For the yield stress $\sigma_{\mathrm{y} . k s i}$, use the yield stress of the actual heat pipe material.

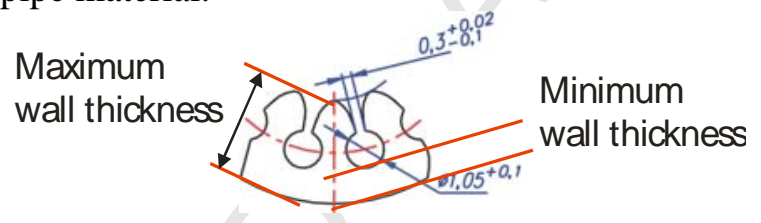

Fig. 4. This figure shows a 1/8-section of a heat pipe in cross-section. The definition of the minimum/maximum heat pipe wall thickness is shown.

(E3) Application to integrated heat pipes in sandwich panel structures: Insert the wall thickness of the sandwich panel's front face-sheet including additional walls (Fig. 5) for $t_{\mathrm{ob}} \cdot \mathrm{t}_{\mathrm{w}}$ and $\mathrm{S}_{2}$ are set equal to zero. For heat pipes, two wall thicknesses are supplied: minimum and maximum wall thickness (Fig. 5): For the calculations, use the maximum wall thickness for $t_{b}$. If the heat pipe material is other than aluminum, use for $t_{b}$ the value as obtained from the equal areal density approach $\left(t_{b}=t_{\text {pipe }} \cdot \rho_{\text {pipe }} / \rho_{\text {Al }}\right)$. For bumper density $\rho_{\mathrm{b}}$, use the density of the Al alloy; for the yield stress $\sigma_{\mathrm{y}, \mathrm{ksi}}$, use the yield stress of the actual heat pipe material.

(E4) Application to carbon-fibre wrapped vessels: Equipment placed behind structure walls (S5) to (S6): For $t_{w}$, use the wall thickness of the carbon-fibre wrapped vessel. $t_{w}$ is calculated according to the following equation:

$$
t_{w}=t_{w, A l}+K_{C F R P} \cdot\left(t_{w, C F R P}\right)^{1 / 3} \cdot \frac{\rho_{C F R P}}{\rho_{A l}}
$$

where $\mathrm{K}_{\mathrm{CFRP}}$ is the adjustment factor for CFRP, $\mathrm{t}_{\mathrm{w}, \mathrm{Al}}$ is the thickness of the Al liner of the carbon-fibre wrapped vessel [cm], $t_{w, C F R P}$ is the thickness of the CFRP layer of the carbon-fibre wrapped vessel [cm], 
$\rho_{\mathrm{Al}}$ is the density of the reference aluminum $\left(2.7 \mathrm{~g} / \mathrm{cm}^{3}\right)$, and $\rho_{\mathrm{CFRP}}$ is the density of the CFRP $\left[\mathrm{g} / \mathrm{cm}^{3}\right]$. For the yield stress $\sigma_{y . k s i}$, the yield stress of the vessel's liner material shall be used.

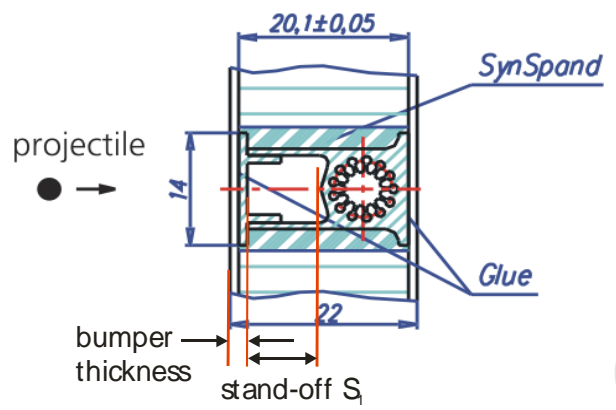

Fig. 5. Definition of bumper thickness and stand-off for integrated heat pipes.

(E5) Application to e-boxes placed behind structure walls: Equipment placed behind structure walls (S1) to (S4): For $t_{b}$, use the value of the e-box casing wall thickness. If the e-box casing wall material is other than aluminum, use for $t_{b}$ the value as obtained from the equal areal density approach with the density of aluminum for normalization $\left(t_{b}=t_{\text {casing }} \cdot \rho_{\text {casing }} / \rho_{\text {Al }}\right)$. For the yield stress $\sigma_{y . k s i}$, use the yield stress of the actual casing wall material. Equipment placed behind structure walls (S5) to (S6): For $t_{w}$, use the value of the e-box casing wall thickness. If the casing wall material is other than aluminum, use for $t_{w}$ the value as obtained from the equal areal density approach with the density of aluminum for normalization ( $\mathrm{t}_{\mathrm{b}}=\mathrm{t}_{\text {casing }} \cdot \rho_{\text {casing }} / \rho_{\mathrm{Al}}$ ). For the yield stress $\sigma_{\mathrm{y} . \mathrm{ksi}}$ use the yield stress of the actual casing wall material.

(E6) Application to battery cells placed behind structure walls: Equipment placed behind structure walls (S1)- to (S4): For $t_{b}$, use the value of the thickness of the battery cell wall (casing). If the material of the battery cell wall is other than aluminum, use for $t_{b}$ the value as obtained from the equal areal density approach with the density of aluminum for normalization $\left(t_{b}=t_{\text {casing }} \cdot \rho_{\text {casing }} / \rho_{\text {Al }}\right)$. For the yield stress $\sigma_{\text {y.ksi, }}$ use the yield stress of the actual casing wall material. Equipment placed behind structure walls (S5) to (S6): For $t_{w}$, use the value of the thickness of the battery cell wall (casing). If the material of the battery cell wall is other than aluminum, use for $t_{w}$ the value as obtained from the equal areal density approach with the density of aluminum for normalization $\left(t_{b}=t_{\text {casing }} \cdot \rho_{\text {casing }} / \rho_{\text {Al }}\right)$. For the yield stress $\sigma_{\mathrm{y} . k s i}$, use the yield stress of the actual casing wall material.

(E7) Application to cables placed behind structure walls: Equipment placed behind structure walls (S2), (S5): From the cable geometry and the materials of the cable components, an effective Al wall thickness is calculated, to be applied in the SRL ballistic limit equation for $\mathrm{t}_{\mathrm{w}}$. Correspondingly, failure of the respective cables is assumed when the effective $\mathrm{Al}$ wall fails, i.e., when spall detachment occurs. Hence, for the yield stress $\sigma_{y . k s i}$, the yield stress of the aluminum shall be used. This approach is a purely engineering one, not reflecting the actual penetration behaviour of fragments into cables. $t_{w}$ is calculated according to the following equation:

$$
t_{w}=K_{\text {cable }} \cdot\left[\sum_{i}^{N_{\text {insul }}}\left(t_{\text {insul }, i} \cdot \frac{\rho_{\text {insul }, i}}{\rho_{\mathrm{Al}}}\right)+\sum_{j}^{N_{c}}\left(t_{c, j} \cdot \frac{\rho_{c, j}}{\rho_{\mathrm{Al}}}\right)\right]
$$

where $\mathrm{K}_{\text {cable }}$ is the adjustment factor for cables, $\mathrm{N}_{\text {insul }}$ is the total number of insulation layers, $\mathrm{N}_{\mathrm{c}}$ is the 
total number of conductor or metallic shielding layer of the cable, $t_{\text {insul, }}$ is the thickness of $i$-th insulation layer of the cable $[\mathrm{cm}], \mathrm{t}_{\mathrm{c}, \mathrm{j}}$ is the thickness of $\mathrm{j}$-th conductor or metallic shielding layer of the cable $[\mathrm{cm}], \rho_{\mathrm{Al}}$ is the density of reference $\mathrm{Al}\left(2.7 \mathrm{~g} / \mathrm{cm}^{3}\right), \rho_{\text {insul, }}$ is the density of i-th insulation layer of the cable $\left[\mathrm{g} / \mathrm{cm}^{3}\right]$, and $\rho_{\mathrm{c}, \mathrm{j}}$ is the density of $\mathrm{j}$-th conductor or metallic shielding layer of the cable $\left[\mathrm{g} / \mathrm{cm}^{3}\right]$.

\subsubsection{Fit coefficients}

Several parameters in the SRL ballistic limit equation need to be fit to the experimental data. These are general fit parameters that are applied to all equipment types, and equipment specific parameters that need to be fit separately for any equipment type. The general fit parameters are $K_{3 S}=1.40$, $\mathrm{K}_{3 \mathrm{D}}=0.4, \mathrm{~K}_{\mathrm{MLI}}=3.0, \mathrm{~K}_{\mathrm{S} 2}=0.1, \mathrm{~K}_{\mathrm{tw}}=1.5, \alpha=1 / 2, \beta=2 / 3, \gamma=1 / 3, \delta=4 / 3$ for $\left(\theta \leq 45^{\circ}\right.$ and $\left.\theta \geq 65^{\circ}\right)$ and $\delta=5 / 4$ for $\left(45^{\circ}<\theta<65^{\circ}\right), \varepsilon=8 / 3$ for $\left(\theta \leq 45^{\circ}\right.$ and $\left.\theta \geq 65^{\circ}\right)$ and $\varepsilon=10 / 4$ for $\left(45^{\circ}<\theta<65^{\circ}\right)$. The specific fit parameters of the SRL BLE for each equipment/structure type are $\mathrm{v}_{\mathrm{t} 1, \mathrm{n}}=3 \mathrm{~km} / \mathrm{s}$ and $\mathrm{v}_{\mathrm{t} 2, \mathrm{n}}=7 \mathrm{~km} / \mathrm{s}$ for the following structure walls: Al H/C SP / Al bumper / MLI+Al H/C SP / MLI+Al bumper, $\mathrm{v}_{\mathrm{t} 1, \mathrm{n}}=4 \mathrm{~km} / \mathrm{s}$ and $\mathrm{v}_{\mathrm{t} 2, \mathrm{n}}=10 \mathrm{~km} / \mathrm{s}$ for standalone MLI as structure wall, $\mathrm{K}_{\mathrm{CFRP}}=0.75$ for carbonfibre wrapped vessels, and $\mathrm{K}_{\text {cable }}=0.35$ for cables.

Obviously, to fit all of these coefficients, a large number of parametric impact tests on the corresponding equipment placed behind a variety of satellite structure walls is required. In the underlying project, [1], only a limited set of test configurations and test data were available, with most of the impact tests having been performed at perpendicular impact, leaving considerable gaps in the validation of the equation especially at oblique impacts.

\section{Ballistic Limit Curves Based on SRL Equation}

In the following, the ballistic limit curves (BLC) for the pressure vessels and the electronics boxes are plotted against the experimental results. The BLCs have been generated by applying the SRL BLE using coefficients listed in the previous chapter. As all experimental data were fitted simultaneously against the SRL BLE with its various coefficients, the BLC could not be optimized for each piece of equipment. Rather, to allow use of a single BLE with a single set of coefficients for all equipment (in all configurations), the data had to be fitted conservatively.

A further fact leading to quite conservative ballistic limit curves is related to the impact probability of fragments on the equipment. Especially, equipment with small lateral extensions, such as pipes, cables, and battery cells, has a small impact probability for damaging fragments. This has been analyzed in detail in [1] for low velocity impact on fuel pipes, but is also applicable to other equipment and other impact velocity regimes (e.g. the shatter velocity regime). Further, penetration of honeycomb sandwich panel structure walls leads to very irregular fragment clouds (size and velocity distribution), compared to thin bumpers.

\subsection{High-pressure vessels}

As failure criterion for gas-filled high-pressure vessels, pressure tightness was selected. The experimental data obtained in hypervelocity impact tests on CFRP/Al high-pressure vessels placed behind the MLI/MetOp Sandwich Panel (Fig. 6) have been fitted to the SRL equation: At $100 \mathrm{~mm}$ 
stand-off between tube/vessel wall and sandwich panel, the experimental results (perforation/no perforation of the vessel wall) are fitted well to the SRL equation. At $200 \mathrm{~mm}$ stand-off, the fit is slightly conservative in the lower shatter velocity range. The curves for zero stand-off between structure wall and vessel surface $\left(S_{2}=0\right)$ have been added in the plots for providing additional information. The values used in the SRL equation are as follows: $\mathrm{t}_{\mathrm{ob}}=0.041 \mathrm{~cm}, \mathrm{t}_{\mathrm{b}}=0.041 \mathrm{~cm}, \mathrm{t}_{\mathrm{w}}=\mathrm{t}_{\mathrm{Al}}+\mathrm{K}_{\mathrm{CFRP}} \cdot \rho_{\mathrm{CFRP}}$. $\left(\mathrm{t}_{\mathrm{CFRP}}\right)^{1 / 3} / \rho_{\mathrm{Al}}=0.472 \mathrm{~cm}, \quad \mathrm{R}_{\mathrm{p} 0.2}=260 \mathrm{MPa}, \quad \rho_{\mathrm{p}}=2.7 \mathrm{~g} / \mathrm{cm}^{3}, \quad \rho_{\mathrm{ob}}=2.7 \mathrm{~g} / \mathrm{cm}^{3}, \quad \rho_{\mathrm{b}}=2.7 \mathrm{~g} / \mathrm{cm}^{3}$, $\mathrm{m}_{\mathrm{a}, \mathrm{MLI}}=0.0447 \mathrm{~g} / \mathrm{cm}^{2}, \theta=0^{\circ}, \mathrm{S}_{1}=3.5 \mathrm{~cm}, \mathrm{~S}_{2}=20 / 10 / 0 \mathrm{~cm}$, bumper material: Al.

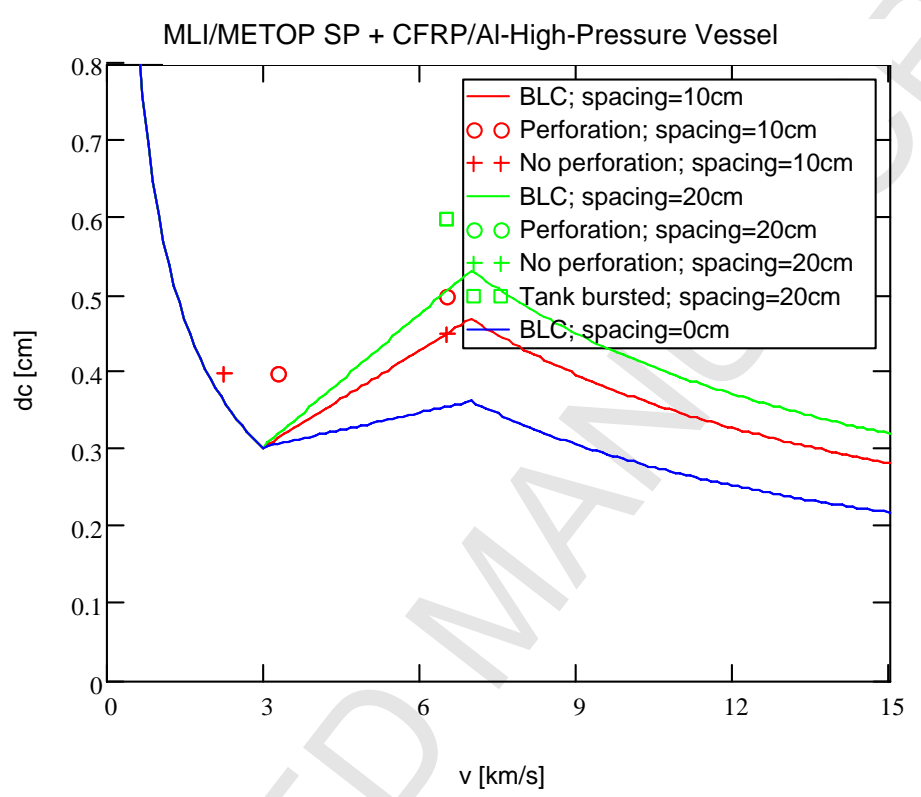

Fig. 6. BLC and experimental results for impact tests on carbon-fibre wrapped pressure vessels with Al liners, with a METOP H/C SP structure wall with MLI placed at a stand-off of $100 \mathrm{~mm}$ and $200 \mathrm{~mm}$ (and $0 \mathrm{~mm}$ ) from the vessel surface. $0^{\circ}$ impact angle.

\subsection{E-boxes}

In Fig. 7, various test results on e-boxes shielded with MLI/MetOp H/C SP structure are plotted against the predictions of the SRL equation. The data added to the plots are distinguished by "perforation", "spall detachment" and "no perforation" of the e-box lid. Fig. 13, left, shows the data at normal incidence $\left(0^{\circ}\right)$, and Fig. 7, right, shows the data at $45^{\circ}$ impact obliquity on e-boxes with a $1.5 \mathrm{~mm}$ lid at $0 \mathrm{~mm}, 100 \mathrm{~mm}$ and $300 \mathrm{~mm}$ stand-off. The values used in the SRL equation are: $\mathrm{t}_{\mathrm{ob}}=0.041 \mathrm{~cm}, \mathrm{t}_{\mathrm{b}}=0.041 \mathrm{~cm}, \mathrm{t}_{\mathrm{w}}=0.1 / 0.15 / 0.2 / 0.3 \mathrm{~cm}, \mathrm{R}_{\mathrm{p} 0.2}=250 \mathrm{MPa}, \rho_{\mathrm{p}}=2.7 \mathrm{~g} / \mathrm{cm}^{3}$, $\rho_{\mathrm{ob}}=2.7 \mathrm{~g} / \mathrm{cm}^{3}, \rho_{\mathrm{b}}=2.7 \mathrm{~g} / \mathrm{cm}^{3}, \mathrm{~m}_{\mathrm{a}, \mathrm{MLI}}=0.0447 \mathrm{~g} / \mathrm{cm}^{2}, \theta=0^{\circ} / 45^{\circ}, \mathrm{S}_{1}=3.5 \mathrm{~cm}, \mathrm{~S}_{2}=0 / 10 / 30 \mathrm{~cm}$, bumper material $=\mathrm{Al}$.

Comparing these results to the predictions from the SRL equation, it is noted that a good to conservative match has been obtained for the tests performed at normal incidence, and very conservative predictions have been obtained for the oblique tests, considering that even projectile 
Schäfer, et al. / International Journal of Impact Engineering

diameters exceeding the predicted critical diameter by about $60 \%$ to $70 \%$ did not result in perforation of the lid. A less conservative match fit to the data was not possible without compromising the quality of the fit of the other oblique data that were fitted to the SRL equation.
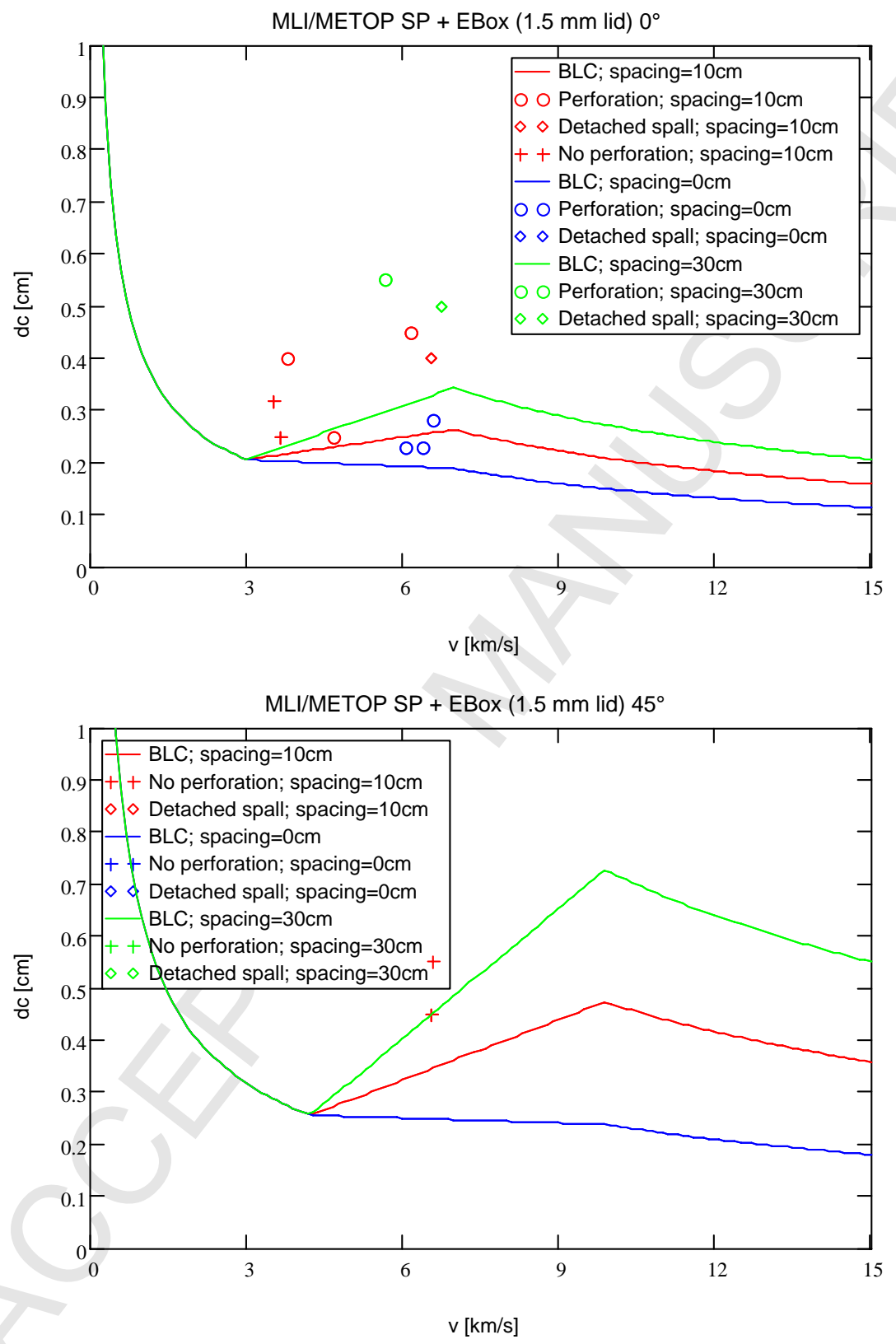

Fig. 7. BLC and experimental results for impact tests on e-box with $1.5 \mathrm{~mm}$ thick Al lid, with a METOP H/C SP structure wall with MLI placed at a stand-off of $100 \mathrm{~mm}$ and $300 \mathrm{~mm}$ (and $0 \mathrm{~mm}$ ) from the lid's surface. Top: $0^{\circ}$ impact angle.

Bottom: $45^{\circ}$ impact angle. 


\section{Benefit Gained From Considering the Equipment's Inherent Shielding Capability}

In Fig. 8, the SRL BLC has been plotted for the MetOp-H/C SP alone and the MetOp- H/C SP plus e-box configuration. This has been done for an e-box with a $1.5 \mathrm{~mm}$ thick lid, adding the experimental data. The stand-off between rear face-sheet of the sandwich panel and the equipment front wall is $100 \mathrm{~mm}$. The benefit gained from considering the structure wall alone and the inherent shielding capability offered by the equipments front cover can now be quantified for these examples.

In the case of the e-box with the $1.5 \mathrm{~mm}$ thick lid, at $7 \mathrm{~km} / \mathrm{s}$, the predicted critical diameter for spall detachment on the rear side of the lid amounts to ca. $2.5 \mathrm{~mm}$ while for the standalone MLI+MetOp sandwich panel the predicted critical diameter is on the order of $0.7 \mathrm{~mm}$ (Fig. 8). The difference in mass between the two critical projectile diameters is a factor of approximately 45 . Thus, when considering the intrinsic shielding capabilities of the e-box lid instead of assuming that the e-box fails if the satellite structure wall placed in front of it is perforated, impact of much larger projectile masses can be considered "safe" for the equipment, i.e., not perforating the front lid of the e-box.

From this assessment, it can be concluded that the risk of failure especially of equipment with high intrinsic protection capability is drastically overestimated if it is assumed that the equipment fails as soon as the structure wall in front of it is perforated. The ballistic limit curves of equipment including the structure wall are all considerably exceeding the ballistic limit curves of the corresponding standalone structure walls. The representative example given in Fig. 8 shows that the benefit in terms of critical projectile mass can amount to between one and two orders of magnitudes when considering the intrinsic protection capability of the equipment.

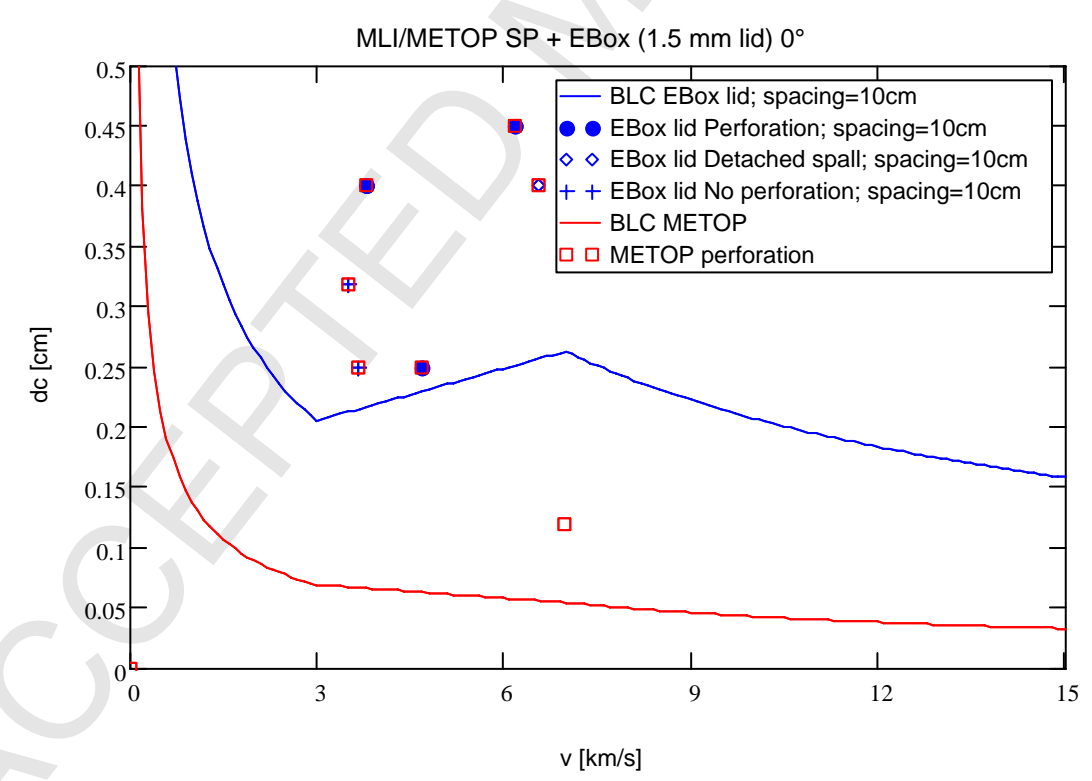

Fig. 8. BLC for a standalone MLI+MetOp sandwich panel and an e-box with a $1.5 \mathrm{~mm}$ thick lid placed at a $100 \mathrm{~mm}$ stand-off to the MLI+MetOp structure wall. Normal projectile incidence $\left(0^{\circ}\right)$. The available experimental data have been added to the plots. 
Schäfer, et al. / International Journal of Impact Engineering

\section{Conclusions}

Under ESA/ESTEC contract, a novel triple plate ballistic limit equation was derived that was fitted to experimental results from hypervelocity impacts on vulnerable equipment. The BLE can be applied for predicting the ballistic limit diameter leading either to perforation of the equipment's front cover/wall (pressure equipment, e-boxes, batteries) or in the case of the harnesses to severing, considering that the equipment is placed behind one of the indicated structure walls.

Using this equation, it was shown that the projectile diameters leading to failure of equipment placed behind structure walls exceed by far the projectile diameters required to perforate the structure walls of the spacecraft only. When considering the intrinsic shielding capabilities of the equipment instead of assuming that the equipment fails if the satellite structure wall placed in front of it is perforated, impact of much larger projectile masses can be considered "safe" against equipment failure induced by penetrating impacts.

Hence, to assess the real risk of spacecraft equipment failure, the intrinsic shielding capability of the equipment needs to be taken into account.

\section{References}

[1] Putzar R, Schäfer F, Romberg O, Stokes H. Vulnerability of Spacecraft Equipment to Space Debris and Meteoroid Impacts. Final Report. Technical Note No. 5 (TN5), ESA Contract 16483/02, 2006; EMI-No. I-15/06.

[2] Putzar R, Schäfer F, Romberg O, Lambert M. Vulnerability of Shielded Fuel Pipes and Heat Pipes to Hypervelocity Impacts. Proc. 4th European Conference on Space Debris, ESA SP-587, 2005; ISBN 929092-898-0.

[3] Putzar R, Schäfer F, Stokes H, Chant R, Lambert M. Vulnerability of Spacecraft Electronic Boxes to Hypervelocity Impacts. Proc. 56th International Astronautical Congress, 2005.

[4] Christiansen EL. Design and Performance Equations for Advanced Meteoroid and Debris Shields. Int. J. Impact Engng., 1993; 14: 145-156.

[5] Drolshagen G, Borge J. ESABASE/DEBRIS. Meteoroid/Debris Impact Analysis Technical Description, Issue 1 for ESABASE version 90.1; 1992.

[6] Reimerdes HG, Stecher KH, Lambert M. Ballistic Limit Equations for the Columbus Double Bumper Shield Concept. Proc. First European Conference on Space Debris, 1993; ESA SD-01.

[7] Christiansen EL, Kerr J. Mesh Double-Bumper Shield: A Low-Weight Alternative for Spacecraft Meteoroid and Orbital Debris Protection, Int. J. Impact Engng., 1993; 14: 169-180.

[8] Schäfer F, Günther L. Impact Testing of ATV-ICC Meteoroid and Debris Protection Shield. Technical Report, ESTEC Contract No. 10556/93/NL/PP(SC) CCN1, 2001; EMI No. E 28/2000. 